\title{
Red Blood Cell Groups and ABH Secretor System as Genetic Indicators of Susceptibility to Rheumatic Fever and Rheumatic Heart Disease*
}

\author{
THOMAS D. DUBLIN, M.D., DR.P.H.; A. DAVID BERNANKE, M.D. ; ELAINE L. PITT, M.D.; \\ BENEDICT F. MASSELL, M.D.; FRED H. ALLEN, JUN., M.D. ; FRANCISCO AMEZCUA, M.D.
}

Brit. med. F., 1964, 2, 775-779

The familial aggregation of rheumatic fever and its sequel, rheumatic heart disease, has long been recognized. Despite well-established evidence that group A haemolytic streptococcus infections may precipitate initial episodes as well as recurrences, the factors determining host susceptibility are still poorly understood. Opinions diverge with respect to the role of inheritance in the aetiology of this disease. Wilson (1962) and her associates have advanced the hypothesis, based on extensive family studies, that susceptibility to rheumatic fever is inherited as a simple autosomal recessive trait. Such a view has not received universal acceptance. This may be due, in part, to the difficulty of replicating Dr. Wilson's elaborate observations covering two or more generations. In addition, the essentially descriptive observations thus far reported have not yet proved fruitful in establishing a basic biochemical or immunochemical mechanism determining susceptibility or resistance.

More recently, and also largely on an empirical basis, various

TABle I.-ABO Blood Groups and Rheumatic Fever and/or Rheumatic Heart Disease

\begin{tabular}{|c|c|c|c|c|c|}
\hline \multirow{2}{*}{ Authors } & \multirow{2}{*}{ No. } & \multicolumn{4}{|c|}{ Frequencies (\%) } \\
\hline & & 0 & A & B & $\mathbf{A B}$ \\
\hline Maxted (Bristol) (1940) $\quad$.. $\quad \ldots\left\{\begin{array}{l}\text { Patients } \\
\text { Controls }\end{array}\right.$ & $\begin{array}{r}200 \\
6,780\end{array}$ & $\begin{array}{ll}47 \cdot 0 \\
43 \cdot 4\end{array}$ & $\begin{array}{l}44 \cdot 5 \\
43 \cdot 9\end{array}$ & $\begin{array}{l}6 \cdot 0 \\
9 \cdot 1\end{array}$ & $\begin{array}{l}2.5 \\
3.6\end{array}$ \\
\hline Walsh and Kooptzoff (Sydney) (1956) $\left\{\begin{array}{l}\text { Patients } \\
\text { Controls }\end{array}\right.$ & $\begin{array}{r}259 \\
1,123\end{array}$ & $\begin{array}{l}42 \cdot 4 \\
44 \cdot 5\end{array}$ & $\begin{array}{l}44 \cdot 0 \\
38 \cdot 2\end{array}$ & $\begin{array}{r}9 \cdot 3 \\
12 \cdot 3\end{array}$ & $\begin{array}{l}4 \cdot 3 \\
5 \cdot 1\end{array}$ \\
\hline Addis (Glasgow) (1959) .. & $\begin{array}{r}538 \\
5,898\end{array}$ & $\begin{array}{l}52.5 \\
53.9\end{array}$ & $\begin{array}{l}32 \cdot 5 \\
32 \cdot 3\end{array}$ & $\begin{array}{l}12 \cdot 0 \\
10 \cdot 8\end{array}$ & $\begin{array}{l}3 \cdot 3 \\
3.1\end{array}$ \\
\hline Clarke et al. (Liverpool) (1960) $\quad \ldots\left\{\begin{array}{l}\text { Patients } \\
\text { Controls }\end{array}\right.$ & $\begin{array}{r}263 \\
16,057\end{array}$ & $\begin{array}{l}39.9 \\
48.8\end{array}$ & \begin{tabular}{|l|}
$44 \cdot 1$ \\
$39 \cdot 2$
\end{tabular} & $\begin{array}{r}13.7 \\
9.5\end{array}$ & $\begin{array}{l}2 \cdot 3 \\
2 \cdot 5\end{array}$ \\
\hline Glynn (Taplow) (1960)* .. & $\begin{array}{r}609 \\
15,046\end{array}$ & $\begin{array}{r}41 \cdot 9 \\
45 \cdot 0\end{array}$ & $\begin{array}{l}42 \cdot 0 \\
42 \cdot 9\end{array}$ & $\begin{array}{r}10.5 \\
8.7\end{array}$ & $\begin{array}{l}5 \cdot 6 \\
3 \cdot 4\end{array}$ \\
\hline Khattab and Ismail (Cairo) (1960).. $\left\{\begin{array}{l}\text { Patients } \\
\text { Controls }\end{array}\right.$ & $\begin{array}{r}120 \\
10,000\end{array}$ & $\begin{array}{l}26.9 \\
36.0\end{array}$ & \begin{tabular}{|}
$42 \cdot 5$ \\
$33 \cdot 6$
\end{tabular} & \begin{tabular}{|l|}
$24 \cdot 2$ \\
$23 \cdot 9$
\end{tabular} & $\begin{array}{l}6.7 \\
6.5\end{array}$ \\
\hline Pham-Huu-Trung et al. (Paris) (1961) $\left\{\begin{array}{l}\text { Patients } \\
\text { Controls }\end{array}\right.$ & $\begin{array}{l}434 \\
257\end{array}$ & $\begin{array}{r}43.5 \\
43.9\end{array}$ & \begin{tabular}{|l|}
$43 \cdot 1$ \\
$43 \cdot 6$
\end{tabular} & $\begin{array}{l}10 \cdot 8 \\
10.5\end{array}$ & $\begin{array}{l}2.5 \\
1.9\end{array}$ \\
\hline Buckwalter et al. (Iowa ;(1962) $\quad . .\left\{\begin{array}{l}\text { Patients } \\
\text { Controls }\end{array}\right.$ & $\begin{array}{r}752 \\
49,979\end{array}$ & $\begin{array}{l}40 \cdot 0 \\
44 \cdot 8\end{array}$ & $\begin{array}{l}45 \cdot 7 \\
42 \cdot 3\end{array}$ & $\begin{array}{l}9 \cdot 8 \\
9 \cdot 4\end{array}$ & 4.5 5 \\
\hline
\end{tabular}

* Quoted from Clarke et al. (1960)

workers have attempted to correlate the occurrence of rheumatic fever and/or rheumatic heart disease with the genetically determined red blood cell groups, particularly the ABO system. Eight such studies are briefly summarized in Table I. It may be seen that some observers find no association ; others observe a

- Based on a report presented at the Symposium on Contributions of Genetics to Epidemiologic Studies of Chronic Disease, University of Michigan, Ann Arbor, 17-19 June 1963. From the Epidemiology and Biometry Branch, NIAMD, NIH, Bethesda, Maryland ; the House of the Good Samaritan, Children's Hospital Medical Center, House of the Good Samaritan, Children's Hospital Medical Center, and the Department of Pediatrics, Harvard Medical School, Boston, Mass. ; and the Blood Grouping Laboratory, Boston, Massachusetts. These studies were supported in part by grant No. HE-04957, Association, and Research Contracts PH 43-62-159 and PH 43-62185, National Institutes of Health. lower frequency of the group $O$ phenotype (and usually a correspondingly higher frequency of group A) among rheumatics than in their control populations.

In several of the studies the authors conclude that chance variation could only remotely account for differences as large as those observed. Yet most of these observations are open to challenge on two grounds. In some studies the diagnostic criteria used in selecting rheumatic subjects are not precisely stated ; since many of the signs and symptoms of this disease are of a protean nature, doubt may arise whether the comparisons made are truly between subjects who have and who have not had rheumatic fever and/or its sequelae. Secondly, and possibly of greater significance, rheumatic fever and/or rheumatic carditis are believed to occur in higher frequency in certain ethnic and socio-economic segments of the population. It does not necessarily follow, therefore, that control groups consisting of volunteer blood donors, individuals hospitalized for other causes, or even the general school-age population in the same community are representative of the same universe from which the rheumatic subjects are drawn.

Glynn et al. (1956, 1959) and Glynn and Holborow (1961) have explored an alternative hypothesis associating the genetic control of susceptibility to rheumatic fever and/or rheumatic carditis with the ability to secrete $\mathrm{ABH}$ blood group mucopolysaccharides in saliva and other body fluids. Though the immunochemical and genetic interrelationships of the ABO, Lewis, and secretor systems are still being explored, the identification of the various phenotypes determined by these genes provides additional criteria for the study of the heritable characteristics of this disease. Glynn's initial observations indicated that rheumatic subjects showed a lower frequency of secretors of $\mathrm{ABH}$ substances in saliva (and a correspondingly increased frequency of the $\operatorname{Le}(\mathrm{a}+)$ blood group) than did healthy schoolchildren in the same community. Pertinent data from this study and from three other subsequently published reports are briefly summarized in Table II. Glynn has ascribed

TABLB II.-ABH Secretion in Rheumatic Fever and/or Rheumatic Heart Disease

\begin{tabular}{|c|c|c|c|c|}
\hline \multirow{2}{*}{\multicolumn{2}{|c|}{ Author }} & \multirow[b]{2}{*}{ No. } & \multicolumn{2}{|c|}{ Frequencies (\%) } \\
\hline & & & Secretor & $\begin{array}{c}\text { Non- } \\
\text { secretor }\end{array}$ \\
\hline Glynn et al. (Taplow) (1959) & $\left\{\begin{array}{l}\text { Rheumatic fever } \\
\text { Healthy school- } \\
\text { children }\end{array}\right.$ & $\begin{array}{l}553 \\
669\end{array}$ & $\begin{array}{l}71 \cdot 1 \\
77 \cdot 1\end{array}$ & $\begin{array}{l}28 \cdot 9 \\
22 \cdot 9\end{array}$ \\
\hline Clarke et al. (Liverpool) (1960 & $\left\{\begin{array}{l}\text { Rheumatic carditis } \\
\text { Controls }\end{array}\right.$ & $\begin{array}{l}263 \\
851\end{array}$ & $\begin{array}{l}72 \cdot 2 \\
75 \cdot 7\end{array}$ & $\begin{array}{l}27 \cdot 8 \\
24 \cdot 3\end{array}$ \\
\hline Pham-Huu-Trung et al. (Paris & $\int \begin{array}{c}\text { Acute rheumatic } \\
\text { fever }\end{array}$ & 434 & $72 \cdot 6$ & $27 \cdot 4$ \\
\hline (1961) & $\begin{array}{l}\text { Non-strept. acute } \\
\text { cont. dis. }\end{array}$ & 271 & $79 \cdot 3$ & 20.7 \\
\hline Buckwalter et al. (Iowa) (1962) & $\left\{\begin{array}{l}\text { Rheumatic fever } \\
\text { Controls }\end{array}\right.$ & $\begin{array}{r}376 \\
1,261\end{array}$ & $\begin{array}{l}74 \cdot 2 \\
77 \cdot 0\end{array}$ & $\begin{array}{l}25 \cdot 8 \\
23 \cdot 0\end{array}$ \\
\hline
\end{tabular}


additional weight to these observations in view of his earlier findings (Glynn and Holborow, 1952) that, in vitro, betahaemolytic streptococci adsorb haptenic blood-group polysaccharides and convert them to complete antigens. This suggested the possibility that a similar sequence of events might transpire during the course of a streptococcal throat infectionthat is, interaction of the streptococci with salivary blood-group substances resulting in a different immunologic response in rheumatic susceptible individuals from that in alternative genotypes.

This increased prevalence of the non-secretor trait among the rheumatics coincided quite closely with that expected had they come from a population of individuals all of whom possessed the non-secretor gene in either the heterozygous or the homozygous form. Such calculations, based on the frequency of the non-secretor gene in a normal population, led Glynn to postulate that only individuals possessing this gene in either single or double dose were susceptible to rheumatic fever, whereas homozygous secretors were not susceptible to this disease.

A major obstacle to the critical testing of this hypothesis arises from our present inability to differentiate directly the homozygous secretors from the heterozygous secretors. It thus becomes necessary to utilize a family analysis wherein the genotypes of secretor parents are identified by the phenotypic characteristics of their offspring. Glynn et al. (1959) suggested a plan of study to explore further this possible association of susceptibility to rheumatic fever with the inherited blood-group systems. This report provides an analysis of some of the data derived from such a combined epidemiological and genetic investigation of 600 rheumatic parents and their mates and offspring.

Simply stated, the Glynn hypothesis postulates that the nonsecretor gene is essential to susceptibility to this disease and those affected are either homozygous non-secretors (se/se) or heterozygous secretors ( $\mathrm{Se} / \mathrm{se}$ ). Consequently, in matings of rheumatic secretors with non-rheumatic non-secretors, one-half of the offspring would be expected to be secretors and the other half non-secretors. This hypothesis has been tested against an alternative null hypothesis wherein the frequency of the secretor trait in the offspring of rheumatics would coincide with that expected were homozygous and heterozygous secretors distributed among rheumatics in the same ratio as found in a normal population. Since the calculated frequency of the nonsecretor gene in the rheumatic population is 0.548 (see Table V), then, under this alternative null hypothesis, the ratio of secretors among the offspring of rheumatic secretor- and nonrheumatic non-secretor matings would be 65 to 35 as shown schematically in Table III.

TABle III.-Expected Genotypic Proportions in Matings of Rheumatic Secretors with Non-rheumatic Non-secretors and in Their Offspring
Under the Glynn Hypothesis $\left(H_{\mathrm{G}}\right)$ and the Null Hypothesis $\left(H_{0}\right)^{*}$

\begin{tabular}{|c|c|c|c|c|c|}
\hline & \multicolumn{3}{|c|}{ Parents } & \multicolumn{2}{|c|}{ Offspring } \\
\hline & \multicolumn{2}{|c|}{$\begin{array}{l}\text { Rheumatic } \\
\text { Secretor }\end{array}$} & \multirow{2}{*}{$\begin{array}{c}\begin{array}{c}\text { Non- } \\
\text { rheumatic } \\
\text { Non- } \\
\text { secretor }\end{array} \\
s e / s e\end{array}$} & \multirow[t]{2}{*}{ Secretor } & \multirow[t]{2}{*}{$\begin{array}{l}\text { Non- } \\
\text { secretor }\end{array}$} \\
\hline & $\mathrm{Se} / \mathrm{Se}$ & Se/se & & & \\
\hline $\begin{array}{c}\text { Glynn } \\
\text { hypothesis }(\mathrm{HG})\end{array}$ & 0 & 1 & 1 & $\frac{1}{2}$ & $\frac{1}{2}$ \\
\hline $\begin{array}{c}\text { Null } \\
\text { hypothesis }\left(\mathrm{H}_{0}\right)\end{array}$ & 0.292 & 0.708 & 1 & 0.646 & 0.354 \\
\hline $\begin{array}{l}q=0.548 \\
\mathrm{p}=0.452\end{array}$ & $\left(\frac{p^{2}}{p^{2}+2 p q}\right.$ & $\left.\frac{2 p q}{p^{2}+2 p q}\right)$ & 1 & $\left(\frac{1}{1+q}\right)$ & $\left(\frac{q}{1+q}\right)$ \\
\hline
\end{tabular}

* Assuming Hardy-Weinberg equilibrium with gene frequencies $p$ and $q$ for the * Assuming Hardy-Weinberg equilibrium with gene frequencies $\mathrm{p}$ and $\mathrm{q}$ for the
$S e$ and $s e$ genes and consequently genotypic proportions $\mathrm{p}^{2}, 2 \mathrm{pq}$, and $\mathrm{q}^{2}$, for $\mathrm{Se} / \mathrm{S} e$, $\mathrm{Se} / \mathrm{se}$, and se/se, respectively.

\section{Design of Study}

Rheumatic-fever subjects were selected for study from the follow-up register of the House of the Good Samaritan, Boston.
Since this institution has been in the forefront of clinical investigation of individuals affected by rheumatic fever, such selection assured to the study subjects for whom there was available a fully documented medical record contemporaneous with the original episode of rheumatic fever and/or the original diagnosis of rheumatic heart disease. Moreover, since these individuals had been carefully followed for many years, their co-operation in this investigation could be anticipated. Invitations to participate were extended to adult patients, some of whom had been under observation for thirty or more years, in the expectation that many of them would be married and have families of their own. They were also asked to return to the follow-up clinic for a periodic clinical examination and for the collection of blood and saliva specimens; in addition they were invited to bring with them their mates and offspring, from whom similar specimens would be obtained. A high response rate was experienced. In a few instances when it was not possible for the family to come to the clinic because of transportation or other problems, a member of the study team visited the home and the collection of specimens was made there. The index case, however, was still seen at the follow-up clinic. In addition to the Good Samaritan subjects, a limited number of suitable rheumatics drawn from the rheumatic-fever clinics of the Boston Lying-in Hospital and the Massachusetts General Hospital and from the private practice of one of us (B. F. M.) were included in the study. The same family study procedures were followed with this group.

The criteria for inclusion in the study included the following: (1) For each index case a fully documented clinical record would be available to establish the occurrence of one or more acute episodes of rheumatic fever or to establish a definitive diagnosis of rheumatic heart disease (Modified American Heart Association-Jones Criteria). (2) A completed repeat cardiovascular examination within one year of participation in this investigation. (3) Diagnostic classification for purposes of this study would be made on the basis of an independent review of the total clinical record by at least two qualified physicians, and in cases of differences in opinion a third independent reviewer would make a final determination. (4) The collection of blood and saliva specimens from each index person, his or her mate, and from their offspring. (5) The mate of each rheumatic subject would be utilized as a control, with respect to genetic phenotyping. The higher frequency of female subjects on the follow-up register of the House of the Good Samaritan resulted in an excess of females in the study population and a corresponding excess of males among the controls. Since the genetic traits under investigation (blood-group types and secretor status) are autosomal, as opposed to sex-linked, it was assumed the resultant distribution of phenotypic frequencies would not be artificially weighted thereby.

\section{Materials and Methods}

(1) Blood specimens were collected by venepuncture, using dry sterile E.D.T.A. Vacutainers ${ }^{1}$; the blood specimens were refrigerated and delivered the same day to the Blood Grouping Laboratory, where the plasma was removed and stored in the frozen state. (2) Fresh saliva specimens were obtained at the same time, frozen, sent to the Blood Grouping Laboratory, defrosted there for testing, and refrozen for storage. (3) All phenotype determinations were done in the Blood Grouping Laboratory.

\section{Results}

\section{ABO, Rh, MN, and Lutheran Blood Group Systems}

Table IV provides a summary of the frequencies of the ABO, $\mathrm{Rh}, \mathrm{MN}$, and Lutheran phenotypes observed among the

\footnotetext{
1 Obtained from Beeton-Dickinson Company, Rutherford, New Jersey.
} 
TABLE IV.-ABO, Rh, MN, and Lutheran Blood-group Frequencies in Rheumatic Subjects and Non-rheumatic Mates (Present Study)

\begin{tabular}{|c|c|c|c|c|c|c|c|c|c|c|c|}
\hline & \multicolumn{7}{|c|}{ ABO Blood Groups } & \multicolumn{4}{|c|}{ MN Blood Groups } \\
\hline & o & $\mathbf{A}_{1}$ & $\mathbf{A}$ & $A_{1} B$ & $\mathbf{A B}$ & B & Total & $M$ & $\mathbf{N}$ & $M N$ & Total \\
\hline $\begin{array}{c}\text { Rheumatics } \\
\text { Non-rheum. } \\
\text { mates .. }\end{array}$ & $276(45 \cdot 4 \%)$ & $183(30 \cdot 1 \%)$ & $63(10 \cdot 4 \%)$ & $25(4 \cdot 1 \%)$ & $6(1 \cdot 0 \%)$ & $55(9 \cdot 0 \%)$ & $608(100 \%)$ & $200(33 \cdot 0 \%)$ & $113(18 \cdot 6 \%)$ & $293(48 \cdot 4 \%)$ & $606(100 \%)$ \\
\hline Total & $557(45.9 \%)$ & $356(29 \cdot 3 \%)$ & $115(9.5 \%)$ & $41(3 \cdot 4 \%)$ & $13(1 \cdot 1 \%)$ & $131(10 \cdot 8 \%)$ & $1,213^{*}(100 \%)$ & $382(31 \cdot 7 \%)$ & $226(18.7 \%)$ & $598(49 \cdot 6 \%)$ & $1206(100 \%)$ \\
\hline \multicolumn{8}{|c|}{ Rh Blood Groups (Abbreviated) } & \multicolumn{4}{|c|}{ Lutheran Blood Groups } \\
\hline & $\begin{array}{c}\text { Rh: } 2 \\
\text { (C Pos.) }\end{array}$ & $\begin{array}{l}\text { Rh: }-2 \\
\text { (C Neg.) }\end{array}$ & $\begin{array}{c}\text { Rh: } 1 \\
\text { (D Pos.) }\end{array}$ & $\underset{\text { (Dh: Neg.) }}{\mathrm{Rh}}$ & $\begin{array}{c}\text { Rh: } 3 \\
\text { (E Pos.) }\end{array}$ & $\begin{array}{l}\text { Rh: }-3 \\
\text { (E Neg.) }\end{array}$ & Total & $(a+)^{L u}(b+)$ & $(a-)^{L u}(b+)$ & $(a+)^{L u}(b-)$ & Total \\
\hline 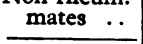 & $424(70 \cdot 7 \%)$ & $176(29 \cdot 3 \%)$ & $529(88 \cdot 2 \%)$ & $71(11 \cdot 8 \%)$ & $176(29 \cdot 3 \%)$ & $424(70 \cdot 7 \%)$ & $600(100 \%)$ & $38(6.4 \%)$ & $558(93.4 \%)$ & $1(0.2 \%)$ & $597(100 \%)$ \\
\hline Total & $848(70 \cdot 3 \%)$ & $358(29 \cdot 7 \%)$ & $1,043(86 \cdot 5 \%)$ & $63(13.5 \%)$ & $360(29.9 \%)$ & $846(70 \cdot 1 \%)$ & $1,206(100 \%)$ & $82(6.8 \%)$ & $1,116(93 \cdot 0 \%)$ & $3(0.2 \%)$ & $1201(100 \%$ \\
\hline
\end{tabular}

- In this study 609 rheumatics and 609 non-rheumatics, a total of 1,218 individuals, were tested. Discrepancies in these totals found in this and subsequent tables can be accounted for by the fact that all phenotype determinations were not completed on every subject. In Tables V and VI indeterminate secretors (6 rheumatics and 5 nonrheumatics) have been omitted.

rheumatic subjects and among their non-rheumatic mates. It may be seen that with respect to these traits the rheumatics and the controls cannot be differentiated. We are not able to confirm the deficit of type $\mathrm{O}$ in a rheumatic fever population reported by Clarke et al. (1960). Further breakdown of the $\mathrm{Rh}$ system into more detailed subgroupings, and extension of the MN system to include all combinations of MNSs reveal no differences between the groups.

\section{Lewis Blood Groups and ABH Secretion in Saliva}

Table $\mathrm{V}$ summarizes observations with respect to the frequencies of secretors and non-secretors of $\mathrm{ABH}$ substances in saliva as determined by agglutination inhibition procedures.

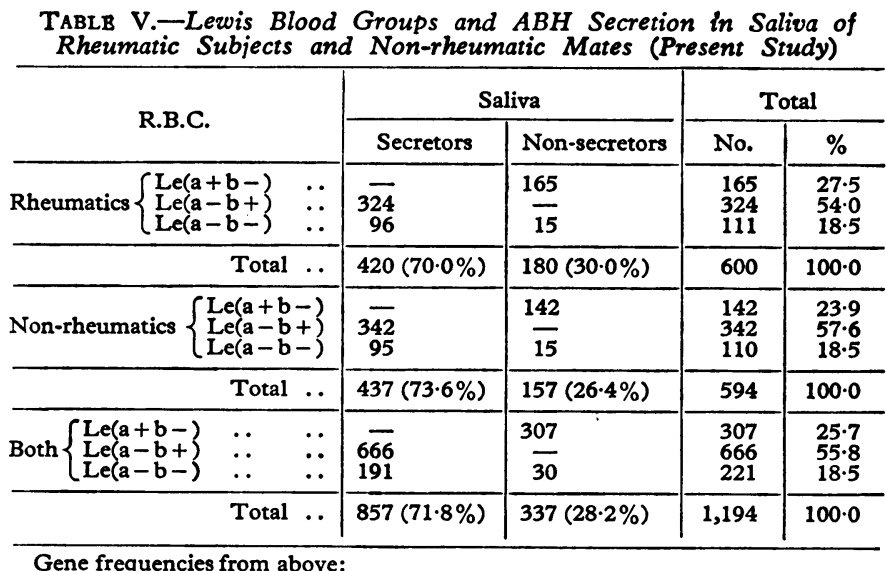

Rheumatics: $S e=0.452$, se $=0.548$. Non-rheumatics: $S e=0.486$, se $=0.514$.

These are matched against the Lewis phenotypes of the blood cells. The frequency of non-secretors of $\mathrm{ABH}$ substances in saliva is somewhat greater in rheumatic subjects than in their non-rheumatic mates. This difference is similar in direction but of lesser magnitude than that reported by Glynn et al. (1959). As a reflection of this, the frequency of $\operatorname{Le}(\mathrm{a}+)$ on the red blood cells is also somewhat greater among the rheumatics. In the present series the magnitude of these differences falls within the range of chance variation, whereas the excess of non-secretors among rheumatics found by the Taplow workers was statistically significant.

As was noted earlier, the number of rheumatic females serving as propositi is in considerable excess of the number of male rheumatics (ratio of almost 2.5 females to 1 male), and among our controls this ratio is reversed. An analysis of sex differences among $\mathrm{ABH}$ secretors and non-secretors has revealed the unanticipated finding shown in Table VI. In the present study female rheumatics are more likely to be $\mathrm{ABH}$ non-secretors than are male rheumatics, and this difference is on the border- line of statistical significance $(0.02<P<0.05)$. Taken separately, female rheumatics appear more likely to be non-secretors than do non-rheumatics of the same sex. Among males, little difference is observable between rheumatics and non-rheumatics. The difference in non-secretion between the rheumatics and their controls is attributable to this higher frequency among the female rheumatics. Analyses of the Lewis blood-group frequencies according to sex reveal similar variations, which are, however, less striking. This could be anticipated because of the close association of the Lewis blood-groups system and the secretor trait. Referring to earlier studies, Glynn et al. (1956) reported no variation in the proportion of secretors and nonsecretors with age or sex, and similarly Clarke et al. (1960)

TABLE VI.-ABH Blood Group Substances in Saliva Among Rheumatic and Non-rheumatic Males and Rheumatic and Non-rheumatic Females (Present Study)

\begin{tabular}{|c|c|c|c|c|}
\hline & & Secretors & Non-secretors & Total \\
\hline Rheumatics $\left\{\begin{array}{l}\text { Males } \\
\text { Females } \ldots\end{array}\right.$ & $\because$ & $\begin{array}{l}133(76.4 \%) \\
290(67.6 \%) \\
\end{array}$ & $\begin{array}{r}41(23.6 \%) \\
139(32.4 \%) \\
\end{array}$ & $\begin{array}{l}174(100 \%) \\
429(100 \%)\end{array}$ \\
\hline Total & .. & $423(70.1 \%)$ & $180(29.9 \%)$ & $603(100 \%)$ \\
\hline Non-rheumatics $\left\{\begin{array}{l}\text { Males } \\
\text { Females }\end{array}\right.$ & 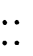 & $\begin{array}{l}320(74 \cdot 4 \%) \\
126(72 \cdot 4 \%)\end{array}$ & $\begin{array}{r}110(25.6 \%) \\
48(27.6 \%)\end{array}$ & $\begin{array}{l}430(100 \%) \\
174(100 \%)\end{array}$ \\
\hline Total & .. & $446(73.8 \%)$ & $158(26 \cdot 2 \%)$ & $604(100 \%)$ \\
\hline
\end{tabular}

observed that "there is no heterogeneity in the ABO group and secretor/non-secretor frequencies between males and females." The data presented here likewise show no variation with age nor heterogeneity within the $A B O, R h, M N$, and Lutheran systems with regard to sex.

\section{Inheritance of the Secretor Trait}

609 rheumatic/non-rheumatic couples have been studied. Table VII presents a summary of data for those 89 families found to be characterized by a rheumatic parent who is a secretor married to a non-rheumatic non-secretor. Of the 239 offspring tested 167 were found to be secretors and 72 nonsecretors. This observed ratio among the offspring corresponds quite closely with the calculated $65 \%$ secretors and $35 \%$ non-

TABLE VII.-Secretor Status of Offspring of Secretor Rheumatic by Non-

\begin{tabular}{c|c|c|c|c}
\multicolumn{3}{c}{ secretor Non-rheumatic Matings (Present Study) } \\
\hline $\begin{array}{c}\text { Family } \\
\text { Size }\end{array}$ & $\begin{array}{c}\text { No. of } \\
\text { Families }\end{array}$ & $\begin{array}{c}\text { Total No. } \\
\text { Offspring }\end{array}$ & $\begin{array}{c}\text { All Offspring } \\
\text { Sec./Non-sec. }\end{array}$ & $\begin{array}{c}\text { Oldest } \\
\text { Offspring } \\
\text { Sec./Non-sec. }\end{array}$ \\
\hline 1 & 16 & 16 & $12 / 4$ & $12 / 4$ \\
2 & 32 & 64 & $42 / 22$ & $21 / 11$ \\
3 & 21 & 63 & $47 / 16$ & $15 / 6$ \\
4 & 11 & 44 & $24 / 20$ & $5 / 6$ \\
5 & 3 & 18 & $15 / 3$ & $3 / 1$ \\
6 & 1 & 9 & $7 / 2$ & $1 / 0$ \\
9 & 89 & 239 & $167 / 72$ & $61 / 28$ \\
\hline Total & 15 & &
\end{tabular}


secretors expected if the frequency of homozygous secretors among the rheumatic parents were the same as that in the normal population. In order to counterbalance any possible bias resulting from weighting due to large family size, the phenotypes of the eldest offspring in each family are recorded in the last column of the table. The frequency ratio of 61 to 28 remains the same.

Table VIII extends this analysis to include the proportions of families segregating for the non-secretion trait-that is, the number of families in which a mating of a rheumatic secretor

TABLE VIII.-Segregation for Non-secretor Trait (se/se) in Offspring of Rheumatic Secretor by Non-rheumatic Non-secretor Matings

\begin{tabular}{|c|c|c|c|c|c|}
\hline \multirow{2}{*}{$\begin{array}{c}\text { Family Size } \\
\text { (No. of } \\
\text { Offspring) } \\
\mathbf{k}\end{array}$} & \multirow{2}{*}{$\begin{array}{c}\text { No. of } \\
\text { Families } \\
\text { N }_{k}\end{array}$} & \multirow{2}{*}{$\begin{array}{c}\text { No. of } \\
\text { Segregating } \\
\text { Families } \\
\text { rk }\end{array}$} & \multirow{2}{*}{$\begin{array}{c}\text { Observed } \\
\text { Ratio }\end{array}$} & \multicolumn{2}{|c|}{ Expected Ratio } \\
\hline & & & & $\mathrm{Ho}$ & $\mathrm{H}_{0}$ \\
\hline $\begin{array}{l}1 \\
2 \\
3 \\
4 \\
5 \\
6 \\
9\end{array}$ & $\begin{array}{r}16 \\
32 \\
21 \\
11 \\
5 \\
3 \\
1\end{array}$ & $\begin{array}{r}4 \\
15 \\
11 \\
9 \\
3 \\
2 \\
1\end{array}$ & $\begin{array}{l}0.250 \\
0.469 \\
0.524 \\
0.818 \\
0.600 \\
0.667 \\
1.000\end{array}$ & $\begin{array}{l}0.500 \\
0.750 \\
0.875 \\
0.938 \\
0.969 \\
0.984 \\
0.998\end{array}$ & $\begin{array}{l}0.354 \\
0.531 \\
0.620 \\
0.664 \\
0.686 \\
0.697 \\
0.707\end{array}$ \\
\hline Total & 89 & 45 & & & \\
\hline
\end{tabular}

Under Glynn hypothesis $(\mathrm{HG})$ the expected segregation ratio of a family of size $k$

is $=1-\left(\frac{1}{2}\right) \mathbf{k}$.
Under the null hypothesis $\left(\mathrm{H}_{0}\right)$ the expected segregation ratio of a family of size $k$ is $=0.7\left(1-\left(\frac{1}{2}\right) k\right)$

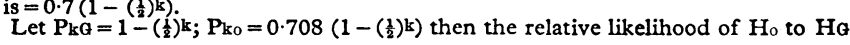

$$
\frac{L\left(H_{0}\right)}{L\left(H_{G}\right)}=\prod_{k=1}^{9} \quad \frac{P_{k 0}^{{ }_{k}}\left(1-P_{k 0}\right)^{N_{k}-r_{k}}}{P_{k G}^{{ }_{k}}\left(1-P_{k G}\right)^{N_{k}-r_{k}}}>10^{9} \text { to } 1
$$

parent with a non-rheumatic non-secretor gives rise to one or more non-secretor offspring, divided by the total number of all such matings. Since the number of children resulting from each mating weights the likelihood of such segregation, an analysis has also been made according to family size. Although the number of families studied in each family-size category is small, it may be seen that the observed segregation ratios correspond somewhat more closely with the ratios expected according to the null hypothesis $\left(\mathrm{H}_{0}\right)$ than those of the Glynn hypothesis $\left(\mathrm{H}_{\mathrm{G}}\right)$. Since the combined likelihood calculated on the basis of family size is a product of the individual likelihoods, it is estimated that the odds against the Glynn hypothesis based on this analysis is in the range of $10^{9}$ to 1 .

\section{Discussion and Summary}

Whereas the place of group A haemolytic streptococcal infection in the aetiology of rheumatic fever has been demonstrated, the evidence for or against an underlying constitutional susceptibility, perhaps on a genetically determined basis and as an essential predisposing factor, is still controversial. The rapid progress made in recent years in immunogenetics and biochemical genetics has opened a new approach to the study of possible associations of genetically determined traits with disease susceptibility.

An abundant literature has appeared attempting to establish associations between blood group types-particularly the ABO system-with disease. Fraser Roberts (1957) has reviewed these associations elsewhere. Wiener (1962) has challenged these investigations on theoretical grounds as well as on the basis of the methods of study utilized. It may be recalled that Glynn's original investigations of the association of $\mathrm{ABH}$ blood-group secretion and rheumatic fever were undertaken not simply on an empirical basis but as an extension of earlier observations indicating that the haemolytic streptococcus could adsorb bloodgroup substances and form with them an immunologically active antigen. In trying to study further some of the factors contributing to the observed relation of secretor status to rheumatic fever Van Rijsewijk and Goslings (1963) found that in a random sample of the total population of a Dutch village the carriers of group A haemolytic streptococcus were more likely to be non-secretors than the non-carriers. In their preliminary communication they felt that a " genetically determined higher infection rate with group A streptococci in nonsecretors compared with secretors with the same attack rate for rheumatic fever in both groups" was "a point of real importance."

The present studies do not support the observations of the Taplow group and of others that the frequency of non-secretors among rheumatics is significantly greater than in non-rheumatics. The differences observed in the frequency of nonsecretors of $\mathrm{ABH}$ substances are in the same direction but of lesser magnitude and not beyond the range of chance variation. With respect to other blood-group traits-specifically the ABO, $\mathrm{Rh}, \mathrm{MN}$, and Lutheran systems-the study population, the rheumatics and their non-rheumatic mates, is homogeneous.

A recent study of secretor frequencies in a normal population in Sweden notes that extensive investigations of this inherited trait are quite sparse. Among several normal populations which have been studied in various regions of the world the frequency of non-secretors has ranged from a low of $11.1 \%$ to a high of $25.4 \%$ (Nerell, 1963). It is of interest that the frequency of $\mathrm{ABH}$ non-secretors among our non-rheumatic population is higher than all normal study groups reported to date. In the light of this great variation in the normal, it becomes even more crucial that study populations be carefully matched against their controls to be certain that differences found are not mere reflections of this wide range.

Differences in secretor status appear to be greater between the sexes in the propositi than between the propositi and their selected controls and than between the sexes among these controls. Since secretion is determined by autosomal genes, these differences may be due to sampling variation, to other factors relevant to the various pathological aspects of rheumatic fever within our study group, or to factors not yet identified. This question will be considered in a subsequent report.

On the basis of our family studies, it is apparent that the presence of the non-secretor gene per se is not an essential requirement for susceptibility to rheumatic fever and/or rheumatic carditis. Among carefully evaluated rheumatic subjects, a sufficient number are homozygous secretors to refute the Glynn hypothesis in its present form.

\section{Addendum}

Since the preparation of this report a laboratory method for differentiating homozygous from heterozygous secretors in blood group $\mathrm{O}$ individuals has been published (Kaklamanis et al., 1964). Applying this method, these investigators have now identified homozygous secretors among a group of rheumatic subjects, an observation inconsistent with their original hypothesis. However, noting an unusual distribution of genotype frequencies in rheumatic subjects (a deficiency of homozygous secretors), they interpret their recent findings as offering " additional evidence that genetic factors influencing susceptibility to rheumatic fever are in some way associated with the secretor phenomenon."

The analyses of secretor phenotypes of the offspring of rheumatic secretor and non-rheumatic non-secretor parents offered in the present report (Tables VII and VIII) have been extended to include all types of matings. These do not indicate a deficiency of homozygous secretors among rheumatic parents. An elaboration of these detailed analyses is planned for a subsequent report.

We wish to express our appreciation of the valuable assistance given the study by Miss Gloria Baker, who supervised the follow-up 
and recall of the Good Samaritan patients. Grateful appreciation is also due to the volunteer members of the Mended Hearts Association of Boston, who assisted and participated in the study. Dr. Seymour Geisser and Dr. Peter Workman, Biometry Section, NIAMD, have assisted in the design of this investigation and in the analysis of data.

\section{REFERENCES}

Addis, G. J. (1959). Scot. med. 7., 4, 547.

Buckwalter, J. A., Naifeh, G. S., and Auer, J. E. (1962). Brit. med. F., 2, 1023 . Clarke, C. A., McConnell, R. B., and Sheppard, P. M. (1960). Ibid.,
1, 21.
Glynn, A. A., Glynn, L. E., and Holborow, E. J. (1956). Lancet, 2, 759. _- (1959). Brit. med. 7., 2, 266.

Glynn, L. E., and Holborow, E. J. (1952). 7. Path. Bact., 64, 775.

(1961) Arthr, and Rheum., 4, 203.

Kaklamanis, E., Holborow, E. J., and Glynn, L. E. (1964). Lancet, 1, 788.

Khattab, T. M., and Ismail, A. A. (1960). 9. Egypt. med. Ass., 43, 441. Maxted, G. R. (1940). Arch. Dis. Childh., 15, 181.

Nerell, G. (1963). Ann. hum. Genet., 27, 119.

Pham-Huu-Trung, Bessis, A., and Mozziconacci, P. (1961). Ann. Pédiat., $8,423$.

Roberts, J. A. F. (1957). Brit. 7. prev. soc. Med., 11, 107.

Roberts, J. A. F. (19. H., and Goslings, W. R. O.'(1963). Brit. med. F., 2,542 .

Walsh, R. J., and Kooptzoff, O. (1956). Aust. Ann. Med., 5, 17.

Wiener, A. S. (1962). Lancet, 1, 813.

Wilson, M. G. (1962). Advances in Rheumatic Fever, 1940-1961. Commonwealth Fund, Hoeber, New York.

\title{
Modes of Onset of Psychotic Depression
}

\author{
PETER HAYS,* M.B., B.S., D.P.M.
}

Brit. med. .., 1964, 2, 779-784

In this department of psychiatry depressions are classified into two principal groups, the main justification for this division being its value in treatment. In effect, with minor terminological differences between one doctor and another, our patients are categorized as having either reactive depressions, meaning comprehensible reactions of the personality to reverses or doleful circumstances, or, on the other hand, what might be called psychotic depressions. A recent presentation of old and new evidence (Kiloh and Garside, 1963) seems to confirm the usefulness of this common distinction. It is the psychotic depressions - the depressions judged likely to respond to electric convulsion treatment (E.C.T.) - that are studied here.

These psychotic depressions have certain clinical features that set them apart from the personality reactions called reactive depressions: for example, the mood is rather fixed, there are often the biological concomitants of depression such as loss of weight, loss of appetite, and constipation, and rather regularly one finds early-morning waking and diurnal variation, the patient feeling at his worst in the morning. One word often used to encompass these depressions is "endogenous"; a depression may be described as "endogenous in type" if obvious depression-producing factors (such as reserpine) operated, but the use of the term endogenous usually means that a syndrome has been recognized which points the way to electric treatment (or, in recent years, a drug with corresponding indications) and which implies that the mood is too fixed and the illness too set for psychotherapy and environmental amelioration to be appropriate as the main therapeutic methods.

\section{Material}

I examined the case summaries of " endogenously" depressed patients who had been at Atkinson Morley's Hospital in the years immediately before the antidepressive drugs came into use. If E.C.T. had been given I read the histories to see if an account of the manner in which the symptoms developed over a period of time was included, the presence of such an account constituting the criterion of selection.

Apart from the above patients, who constitute most of the material, any depressed patients presenting during late 1962 and early 1963 who were thought suitable for E.C.T. were also

\footnotetext{
- Senior Lecturer in Psychiatry, St. George's Hospital, London.
}

seen, and accounts were obtained of the mode of onset of their illnesses, provided that the mode of onset had not been disturbed by the use of antidepressive drugs.

The work fell into four phases, the early results leading to further explorations, and it is convenient to present the methods and results in a correspondingly consecutive manner.

\section{Method 1}

Dr. J. A. Fraser Roberts kindly advised me at this stage; he suggested that I map the mode of development of the symptoms in a graphic form, offering at the same time guidance about scoring and presentation.

Essentially a patient's clinical state at a given point in time was represented by a histogram. On the histogram a set of symptoms was recorded, with some indication of the severity of each symptom. Such histograms were constructed for the syndrome at the time of presentation and for each threemonthly period preceding this. In this way a series of histograms was available for each patient, chronologically arranged, and together giving a graphic representation of the manner in which the illness had developed.

The symptoms considered are shown in Fig. 1, and are those commonly or frequently present in psychotic depressions. It will be seen that symptoms are roughly grouped, those in black being thought most characteristic of the syndrome and those on the right (hatched) being symptoms which, though commonly enough found in psychotic depression, are not in themselves diagnostic of the state; indeed, these last symptoms (anxiety, symptoms increasing towards evening, and difficulty

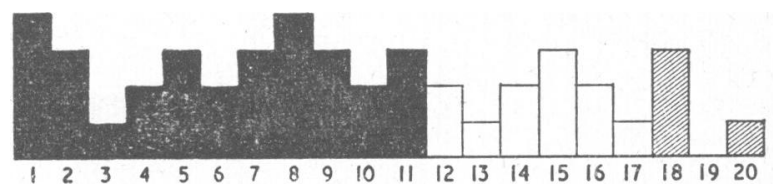

FIG. 1.-Key :-1: Suicidal ideas. 2: Depression. 3 : Retardation. 4: Self-reproach. 5: Worse in mornings. 6: Early waking. 7: Indecision. 8: Loss of reactivity. 9: Loss of interest 10: Loss of energy 11: Loss of concentration 12. Los 12: Loss weight. 15: General somatic symptoms. 16: Gastro-intestinal symptoms. 17: Obsessional symptoms. $18:$ Anxiety.
19: Worse in evenings. 20: Difficulty in falling asleep. 